\title{
Entre o índio real e o índio imaginado: estudo de percepção sobre o olhar de moradores metropolitanos acerca das comunidades indígenas na contemporaneidade
}

\section{Between the real indian and the imagined indian: study of perception on the view of metropolitan residents about contemporary indigenous communities}

\section{Entre lo indio real y lo indio imaginado: estudio de la percepción sobre la visión de los residentes metropolitanos sobre las comunidades indígenas contemporâneas}

José Dias Neto ${ }^{1}$ http://orcid.org/0000-0002-4639-3335 José Antônio Souza de Deus ${ }^{2}$ http://orcid.org/0000-0002-1737-4960

\footnotetext{
${ }^{1}$ Doutorando em Geografia pelo Instituto de Geociências da Universidade Federal de Minas Gerais- UFMG-Belo Horizonte-Brasil, Integrante do Grupo de Estudos Culturais e Etnogeográficos (GECES/UFMG) - josedineto@ yahoo.com.br.

${ }^{2}$ Doutor em Geografia pela Universidade Federal do Rio de Janeiro- UFRJ- Brasil, e pela Universidade Federal de Minas Gerais UFMG-Brasil, Professor (associado IV) credenciado do Programa de Pós-Graduação em Geografia - UFMG- Belo HorizonteBrasil, email: jantoniosdeus@uol.com.br.
}

\section{Resumo}

Este artigo é decorrente da dissertação de mestrado intitulada "Aqui e Lá: Olhares e fronteiras entre a comunidade indígena Pataxó e a sociedade envolvente de Carmésia/MG”, apresentada ao Departamento de Geografia da Universidade Federal de Minas Gerais, com o propósito de avaliar a percepção estabelecida na metrópole a respeito das comunidades indígenas atualmente. Para tanto, se valeu de metodologia qualitativa, através da realização de entrevistas em profundidade conduzidas com roteiro semiestruturado junto a moradores de Belo Horizonte, além da elaboração de mapas mentais por alunos do ensino fundamental de uma escola pública em município da região metropolitana de Belo Horizonte. Os principais resultados apontam para uma divergência entre o índio real e o índio que existe no imaginário das pessoas.

Palavras-chave: Comunidades indígenas. Metrópole. Percepção.

\begin{abstract}
This paper is a result of the master's dissertation entitled "Aqui e Lá: Olhares e fronteiras entre a comunidade indígena Pataxó e a sociedade envolvente de Carmésia/MG”, presented to the Department of Geography of the Universidade Federal de Minas Gerais, with the purpose of evaluating the perception established in the metropolis about the indigenous communities today. For this, it used a qualitative methodology, through indepth interviews conducted with semi-structured script with residents of Belo Horizonte, in addition to the elaboration of mental maps by elementary school students from a public school in a city in the metropolitan region of Belo Horizonte. The main results point to a divergence between the real indian and the indian that exists in people's perception.
\end{abstract}

Keywords: Indigenous communities. Metropolis. Perception.

\section{Resumen}

Geopauta, Vitória da Conquista, ISSN: 2594-5033, V. 4, n. 2, 2020, (p. 91-108) http://periodicos2.uesb.br/index.php/geo 
Este artículo es el resultado de la tesis de maestría titulada "Aqui e Lá: Olhares e fronteiras entre a comunidade indígena Pataxó e a sociedade envolvente de Carmésia/MG”, presentada al Departamento de Geografía de la Universidade Federal de Minas Gerais, con el propósito de evaluar la percepción establecida en la metrópoli con respecto a las comunidades indígenas de hoy. Con este fin, utilizó una metodología cualitativa, a través de entrevistas en profundidad realizadas con cuestionarios semiestructurados con residentes de Belo Horizonte, además de la elaboración de mapas mentales por estudiantes de primaria de una escuela pública en un municipio de la región metropolitana de Belo Horizonte. Los principales resultados apuntan a una divergencia entre el indio real y el indio que existe en la imaginación de las personas.

Palabras clave: Comunidades indígenas. metrópolis. Percepción.

Recebido em: 22/04/2020

Aceito para publicação em: 30/06/2020

Publicado em 20/07/2020

\section{Introdução}

Atualmente, as comunidades indígenas, em sua maioria, se localizam em áreas distantes das grandes cidades. Em virtude disso, as informações que majoritariamente se tem nesses lugares a respeito dos povos indígenas são aquelas obtidas secundariamente, com destaque para a veiculação midiática que, em função do destacado protagonismo sociopolítico das culturas emergentes, cada vez mais tem difundido matérias a esse respeito, sobretudo, relatando os conflitos envolvendo as forças hegemônicas e os grupos étnicos minoritários, contribuindo para a formatação de uma visão coletiva/popular sobre a questão. E é sobre essa percepção que queremos refletir, haja vista que do ponto de vista epistemológico, ela tende a se diferenciar da percepção que a sociedade envolvente tem a respeito das comunidades indígenas, exatamente em função do distanciamento/aproximação territorial entre esses dois segmentos sociais.

A metodologia que fundamentou esta pesquisa é qualitativa e utiliza como embasamento teórico e conceitual as reflexões propostas e estabelecidas no campo da Fenomenologia. Segundo Holzer (2010), a Fenomenologia tem subsidiado trabalhos na área da Geografia, pelo menos, desde 1920, se constituindo enquanto base teórica e metodológica de importantes geógrafos, “entre os quais se destacam Sauer, Dardel, Lowenthal e Kirk" (HOLZER, 2010, p. 37). 
Em busca de uma abordagem fenomenológica do objeto de análise, foi realizado levantamento da percepção da metrópole de duas formas: 1. Através da aplicação de entrevistas semiestruturadas com moradores de Belo Horizonte ${ }^{3}$, no intuito de captar as percepções e valores que estes possuem a respeito das comunidades indígenas; e 2. Mediante aplicação de mapas mentais junto a alunos do ensino fundamental de uma escola pública situada na região metropolitana belohorizontina ${ }^{4}$, com a finalidade de aprofundar a percepção da população urbana a respeito das comunidades indígenas atualmente.

Segundo Deus e Rodrigues (2015), a utilização de entrevistas com roteiro semiestruturado no contexto dos estudos geográficos de viés humanista-fenomenológico caracteriza-se como procedimento fecundo, uma vez que oportuniza o contato direto e a inserção do pesquisador no universo analisado ao propiciar o diálogo aberto e em profundidade, possibilitando a busca pela apreensão de sentidos e significados da realidade experimentada pelos sujeitos acerca do seu mundo vivido.

Ademais, a elaboração de mapas mentais foi empregada como instrumento metodológico para complementação da avaliação da percepção dos sujeitos a partir da representatividade imagética espacial, abordagem que se aproxima à Fenomenologia da Percepção (KOZEL, 2009). Nesse sentido, o intento de captar a percepção da população infantil se mostra uma construção profícua, pois, pode possibilitar uma abordagem mais completa do objeto de análise ao incorporar em seu escopo também este público, além de considerar a formação do pensamento de uma próxima geração a respeito das comunidades indígenas, dos processos de transmissão e reprodução sócio-culturais e da própria forma como essa percepção tem sido culturalmente construída. Nessa perspectiva, Claval (2014) sugere que "as crianças assimilam conhecimentos, atitudes e valores observando e imitando o que se faz à sua volta; as lições recebidas dos adultos destacam os símbolos dos quais os lugares são carregados" (CLAVAL, 2014, p. 23).

\footnotetext{
${ }^{3}$ Aplicadas presencialmente e através de formulário eletrônico de pesquisa, com o auxílio da plataforma Google Formulários, cuja utilização foi de grande relevância para os objetivos desse levantamento de dados, haja vista que a aplicação de entrevistas presenciais, em virtude da simpatia do senso comum em relação às causas indígenas, foram marcadas apenas por percepções de viés positivo sobre os povos indígenas; já os formulários eletrônicos, por assegurarem o anonimato do respondente, foi um ambiente no qual os entrevistados mostraram-se mais à vontade para apresentar sua real opinião sobre as comunidades indígenas, tendo sido relatadas tanto percepções num sentido mais positivo, quanto negativo, como, por exemplo, pudemos verificar através da menção de um entrevistado que afirmou que, na sua opinião, "a demarcação de terras indígenas é um atraso ao desenvolvimento tecnológico do país" (sic).

${ }^{4}$ O levantamento dos dados em campo foi realizado entre os meses de janeiro e março de 2019.
} 
Em síntese, este artigo pode ser classificado como um estudo de percepção. E, conforme orienta Amorim Filho (1987), os estudos de percepção estariam relacionados às formas de comportamento das pessoas no lugar com base nos seus sentimentos, valores, experiências e imagens subjetivas. Já Goodey e Gold (1986), ao resgatarem as intenções e origens sobre a formação de uma Geografia da Percepção, sugerem a emergência de uma abordagem na qual os comportamentos dos indivíduos nos lugares seriam entendidos e sustentados em concepções subjetivas do mundo.

Sob uma perspectiva fenomenológica, os estudos de percepção ambiental passaram, aliás, a ocupar parte da agenda das pesquisas geográficas, surgindo como uma alternativa para a análise do comportamento de indivíduos e grupos sociais a partir das imagens subjetivas/intersubjetivas construídas a respeito do seu mundo vivido. De acordo com Kozel (2009), as imagens mentais construídas na trajetória trilhada a partir da vivência dos indivíduos nos lugares, intermediada pela percepção, estariam relacionadas ao conhecimento espacial adquirido pelos sujeitos. Nessa perspectiva, a vida cotidiana constituiria o fundamento para a construção da percepção.

Com base nesses princípios teorico-metodológicos, buscamos captar a percepção constituída na metrópole acerca das comunidades indígenas, cuja importância foi ressaltada por pesquisadores como Darcy Ribeiro, conforme expresso a seguir.

Resta por fazer o estudo da interação entre tribos indígenas e a sociedade brasileira na década atual. (...) A partir de 1960 parece ter tido início um novo período nas relações entre índios e brasileiros, cujas características básicas mal se configuram. Efetivamente, nos últimos anos, ocorreram várias transformações na sociedade brasileira que a lançaram com violência ainda maior sobre os grupos tribais (RIBEIRO, 1996, p. 16-17).

Percebemos, nas palavras do autor, a importância de trabalhos que tenham por propósito refletir sobre a relação entre comunidades indígenas e não indígenas no contexto brasileiro, o que serve para justificar a análise aqui apresentada.

\section{O ambivalente e contraditório olhar da metrópole sobre as comunidades indígenas}

O olhar da metrópole sobre as comunidades indígenas é um tema que tem sido explorado por pesquisas e trabalhos acadêmicos. De acordo com Schneider e Verás 
Neto (2015), em pesquisa que buscou analisar a forma na qual os índios são percebidos na cidade de Porto Alegre, prevalece nos contextos urbanos a noção de invisibilidade dos direitos indígenas, pois, segundo os autores, estes seriam espaços nos quais a presença indígena figura como algo ilegítimo, o que seria decorrente da visão colonialista e romantizada do índio em interação com a natureza. Essa invisibilidade, que tem como resultados o desconhecimento e o distanciamento (físico e cultural), está presente também na análise de Lima e Almeida (2010), que avaliaram as representações sociais construídas sobre os índios em Sergipe. De acordo com esses autores, prevalece na cidade uma representação "cujo núcleo central é formado por elementos que se referem a um tempo passado e remoto, ou que denotam a distância física e cultural (como "matas", “florestas", “nudez", "pintura")" (LIMA; ALMEIDA, 2010, p. 17), revelando um imaginário a respeito do que os habitantes de grandes centros urbanos entendem ser o índio, do qual alguns aspectos também puderam ser observados nas entrevistas realizadas com moradores de Belo Horizonte, as quais denotaram a representação de um índio ausente ou invisível, perdido historicamente no tempo através da imagem dos povos indígenas nos tempos remotos da colonização.

Por essa razão, o primeiro aspecto a ser regitrado em relação à percepção das comunidades indígenas por parte dos moradores de Belo Horizonte é justamente o baixo conhecimento demonstrado pelos entrevistados a respeito da questão, denotando a ausência e invisibilidade indígenas no contexto urbano da capital mineira. Muito em virtude disso, as percepções reveladas pelas entrevistas realizadas em Belo Horizonte são confusas, ora os entrevistados trazem questões genéricas que tendem para uma avaliação de cunho positivo dos índios, do tipo, "primeiros habitantes do Brasil", "verdadeiros donos da terra", "injustiçados pelo homem branco"; ora assumem elementos de um viés mais negativo, como, "alcoólatras", "violentos", “impedem o desenvolvimento do país", classificações genéricas que ratificam o baixo conhecimento sobre as comunidades indígenas brasileiras nas grandes cidades cujos habitantes, na ausência de informações qualificadas, utilizam representações a respeito dos índios que permeiam o senso comum, marcado por um "cenário complexo de silêncio e invisibilização social que habitam e são construídas as representações sociais sobre os índios no Brasil." (LIMA; ALMEIDA, 2010, p. 18).

Nesse contexto, prevalece uma: 
Visão distanciada do índio, neutra, que não cria processos de comparação e que traduz, conforme nosso entendimento, a invisibilidade e indiferença que caracterizam a visão dominante dos brasileiros que não mantêm contato com os índios. Essa visão, se não produz antipatia ou negatividade, também não produz solidariedade em relação a esse grupo (LIMA; ALMEIDA, 2010, p. 24, grifo nosso).

Esse é o cenário prevalente nas entrevistas realizadas em Belo Horizonte, conforme os relatos listados a seguir, nos quais podemos observar opiniões genéricas e que, de fato, denotam baixo conhecimento por parte dos entrevistados em relação às comunidades indígenas brasileiras:

Os índios são um povo muito batalhador, estão na luta há séculos sem o apoio de ninguém. Eles têm que ser respeitados. Índio tem que ter direito a terra e ser respeitado (sic) (Informação verbal, moradora de Belo Horizonte, 49 anos) $)^{5}$.

Sei que são um povo injustiçado, que perdeu terras, conhecimentos e costumes com a chegada do homem branco ao Brasil (sic) (Informação verbal, morador de Belo Horizonte, 40 anos) ${ }^{6}$.

Tem muito índio sem vergonha, que surrupia, mas é uma minoria que é assim. O branco vai lá e ensina tudo que é bandalheira, é o branco que leva a desordem (sic) (Informação verbal,) ${ }^{7}$.

[Os índios] precisam de atenção porque, na verdade, quem precisa de licença somos nós, eles já estavam aqui (sic) (Informação verbal) ${ }^{8}$.

Tais relatos, por serem permeados por visões genéricas e do senso comum sobre as comunidades indígenas, exprimem um baixo conhecimento acerca do assunto pelos entrevistados, que pode ser avaliado como decorrente da invisibilidade dos índios nas metrópoles. Por exemplo, quando um entrevistado menciona a injustiça acometida aos povos indígenas brasileiros com a chegada do colonizador europeu, de fato ele cita um importante elemento na relação entre a sociedade brasileira e as comunidades indígenas, porém, ao se restringir a este fato, também deixa de considerar os desafios e as dinâmicas que lhes foram impostas ao longo de mais de 500 anos de história. É como se

\footnotetext{
${ }^{5}$ Entrevista realizada por José Dias Neto, entre os meses de janeiro e março de 2019, na cidade de Belo Horizonte. Registrada mediante gravador.

${ }^{6}$ Idem

${ }^{7}$ Idem

${ }^{8}$ Entrevista realizada por José Dias Neto, entre os meses de janeiro e março de 2019, na cidade de Belo Horizonte. Registrada mediante formulário eletrônico. No registro das entrevistas respondidas via formulário eletrônico, não é possível se vincular as respostas aos respondentes e, por essa razão, a idade do entrevistado(a) não pôde ser registrada. $\mathrm{O}$ mesmo vale para todos os demais recortes de fala de entrevistas aplicadas via formulário eletrônico.
} 
os processos socio-territoriais e culturais que envolvem tanto a sociedade brasileira quanto as comunidades indígenas fossem estáticos, não tendo mudado/se transformado com o decorrer do tempo. Já quando o entrevistado resolve apresentar algum tipo de classificação, seja ela de viés positivo ou negativo sobre os índios, como ao relatar que são "um povo trabalhador" ou que são "sem-vergonhas", a leitura que se pode fazer é de que no momento da entrevista, por não possuir um conhecimento qualificado sobre o tema, ele acessa o seu arquivo mental de informações a respeito e as utiliza como embasamento discursivo, embora as respostas sejam rasas e pouco exploratórias, mesmo com o esforço, no momento de aplicação dos formulários presenciais, em estimularmos uma reflexão mais crítica e aprofundada por parte do respondente. Por conseguinte, os questionários aplicados em Belo Horizonte foram marcados por respostas compostas por poucas palavras e frases, ainda que o caráter exploratório da pesquisa tenha servido de balizador à forma na qual as entrevistas foram conduzidas, o que nos permite avaliar que, na realidade, aquele tema não parecia familiar aos entrevistados.

Ademais, além de reportarem relatos pouco qualificados sobre as comunidades indígenas, os entrevistados também admitiram, por conta própria, quando questionados acerca do que sabiam sobre as comunidades indígenas brasileiras, que não sabem nada ou sabem muito pouco a respeito, o que aponta para a noção de baixo conhecimento que leva à invisibilização das comunidades indígenas nesses grandes centros, áreas que, via de regra, estão mais distanciadas dos territórios indígenas.

O que podemos notar, assim, é que na metrópole, o "índio real" tende a não ser percebido, dando lugar à ideia de um "índio imaginado", que se vincula aos elementos naturais e às imagens das comunidades indígenas difundidas pelo senso comum e/ou compulsoriamente veiculadas na mídia em função de algum conflito ou situação específica, bem como nos livros didáticos que, segundo sinalizado pelos próprios entrevistados, são as principais fontes de informação referentes à questão indígena. Este é outro importante aspecto da percepção da metrópole sobre as comunidades indígenas que converge com a análise de Lima e Almeida (2010), calcada nas representações que delimitam a distância física, mas também cultural (e acrescentamos temporal) entre esses dois lugares. Por este motivo as referências às florestas, ao índio nu, às vestimentas tradicionais e pinturas corporais, aos hábitos de vida primários, às construções típicas; foram algo bastante comum nas entrevistas. 
Outro elemento comumente presente no discurso dos entrevistados refere-se aos conflitos estabelecidos entre comunidades indígenas e sociedade não-indígena, os quais foram remetidos, sobretudo, ao período colonial brasileiro. Nota-se, mais uma vez, a importância dos processos históricos envolvendo os índios no Brasil para a formatação de uma percepção sobre as comunidades indígenas na cidade. Conflitos contemporâneos, como aqueles estabelecidos entre índios e garimpeiros e/ou fazendeiros, também foram citados, embora em menor escala. De toda sorte, a análise exploratória da percepção dos conflitos envolvendo comunidades indígenas se manteve no plano da superficialidade e do senso comum, uma vez que não foram reportadas respostas específicas e embasadas em situações concretas que apontassem, por exemplo, algum conflito; e as referências se estabeleceram sempre no campo da impessoalidade, conforme podemos observar nos relatos a seguir:

É uma guerra lascada, com garimpeiro, fazendeiro, os índios não têm sossego. O fazendeiro e o garimpeiro deviam ter respeito, o que é do índio, é do índio (sic) (Informação verbal, morador de Belo Horizonte, 28 anos) $)^{9}$.

A maioria [das comunidades indígenas] está perdendo suas origens e até mesmo esquecendo a língua devido ao avanço do homem branco nas matas (sic) (Informação Verbal) ${ }^{10}$.

Tenho pouco conhecimento no assunto, mas soube de alguns embates entre as comunidades e o governo com relação à demarcação de terras (sic) (informação Verbal) ${ }^{11}$.

O que podemos perceber, mais abrangentemente, é um cenário de baixo conhecimento sobre as comunidades indígenas brasileiras no contexto urbano atualmente, o que pode estar vinculado à questão da falta de proximidade territorial, uma vez que estando as comunidades indígenas localizadas distantes da cidade, o interesse dos belo-horizontinos por informações qualificadas e o próprio acesso a elas diminui proporcionalmente, se restringindo ao que é veiculado na grande mídia ou ao

\footnotetext{
${ }^{9}$ Entrevista realizada por José Dias Neto, no mês de março de 2018, na cidade de Belo Horizonte. Registrada mediante gravador.

${ }^{10}$ Entrevista via formulário eletrônico com Morador de Belo Horizonte. Entrevista realizada por José Dias Neto, entre os meses de janeiro e março de 2019, na cidade de Belo Horizonte. Registrada mediante formulário eletrônico. No registro das entrevistas respondidas via formulário eletrônico, não é possível se vincular as respostas aos respondentes e, por essa razão, a idade do entrevistado(a) não pôde ser registrada. O mesmo vale para todos os demais recortes de fala de entrevistas aplicadas via formulário eletrônico.

${ }^{11}$ Entrevista via formulário eletrônico com Morador de Belo Horizonte. Entrevista realizada por José Dias Neto, entre os meses de janeiro e março de 2019 ,
} 
que já faz parte do conhecimento prévio do indivíduo. Na perspectiva indígena, prevalece sua invisibilidade na metrópole.

Todavia, destaca-se alguns entrevistados que demostraram maior nível de esclarecimento e criticidade sobre a questão indígena, em sua maioria com formação em cursos de nível superior na área de Ciências Humanas, o que pode ter contribuído para este maior grau de consciência, conforme se observa nos relatos seguintes:

Existem inúmeras etnias e dialetos indígenas no Brasil. As maiores populações indígenas são dos Ticuna e Guarani. Grupos indígenas estão espalhados por todo o território nacional, porém a maior concentração é na região norte do país. Uma das maiores reivindicações da comunidade indígena é a demarcação de terras, [o fim da] degradação do meio ambiente, expansão urbana, mineração e a agropecuária. Além disso, os principais problemas enfrentados pela comunidade são o alcoolismo e o uso de drogas (sic) (informação verbal) ${ }^{12}$.

Na minha opinião entendo que a cultura indígena deve ser preservada, pois faz parte da formação e construção do Brasil. Entendo que a cultura também não é estática e ao longo do tempo ela se transforma. Além disso, os índios não possuem representatividade expressiva no Poder Legislativo, o que pode acarretar no descaso de suas reivindicações. Ademais, sei que há uma relação entre preservação ambiental e comunidade indígena (sic) (informação verbal) ${ }^{13}$.

São comunidades (no plural), porque estamos falando de muitas culturas, muitos indígenas. São povos que precisam ter seus direitos reconhecidos, em nome de tornar efetivos os direitos humanos para a nação brasileira. Os indígenas não foram incorporados nos direitos de cidadania, e nem [tiveram] reconhecida sua diversidade; portanto, ao passo que ainda não tiveram sua cultura respeitada e suas reivindicações atendidas, nós, enquanto povo brasileiro, não seremos um Estado nação dito "civilizada" baseada em direitos e muito menos uma democracia real (sic) (informação verbal) ${ }^{14}$.

Essas entrevistas destacam-se no conjunto dos dados coletados como componentes de um grupo de respondentes de perfil similar, conforme já citado, constituído por pessoas com formação (concluída ou em curso) em nível superior, especificamente na área de Ciências Humanas, o que nos possibilita diferenciar esse rol de entrevistados do restante do universo da população, e que nos remete ao entendimento de que os indivíduos com esse perfil específico tendem a denotar uma percepção sobre as comunidades indígenas diferenciada do restante da população nos

\footnotetext{
${ }^{12}$ Idem ibidem.

${ }^{13}$ Idem ibidem.

${ }^{14}$ Idem ibidem.
} 
centros urbanos; e cuja característica é marcada pela reflexão crítica e profundidade argumentativa.

Um importante aspecto a se destacar é que mesmo com a prevalência da invisibilidade indígena no contexto urbano denotada a partir do baixo conhecimento revelado pelos entrevistados na metrópole, ainda assim, identificamos nas entrevistas realizadas em Belo Horizonte uma relativa simpatia em relação às comunidades indígenas, o que pode estar ligado ao alcance do paradigma multiculturalista e à difusão dos seus valores na sociedade contemporânea.

Destarte, quando os entrevistados foram perguntados se eles se importam com as comunidades indígenas, se consideram-se solidários a elas, o resultado foi o seguinte:

Gráfico 1 - Você se importa com as comunidades indígenas, se considera solidário a estas causas?

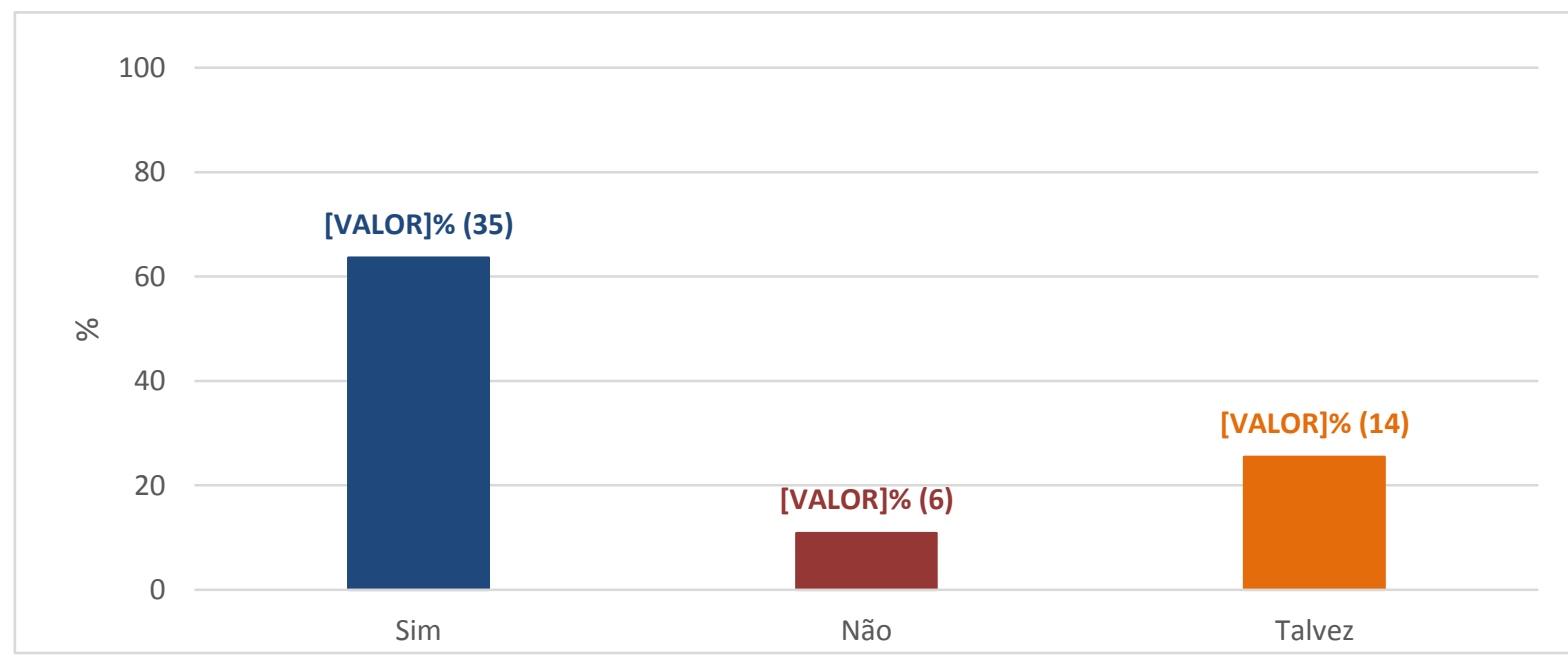

Fonte: DIAS NETO (2019).

Segundo representado pelo gráfico, a maioria dos entrevistados $(63,6 \%)$ afirmou se importar com as comunidades indígenas. Neste sentido, as pessoas se disseram a favor da demarcação de terras e também de questões relativas ao direito indígena, por exemplo.

No decorrer das entrevistas, os entrevistados foram solicitados também que avaliassem, em uma escala de 0 a 10, o seu atual grau de preocupação com as causas indígenas atualmente. Os resultados seguem representados. 
Gráfico 2 - Em uma escala de 0 a 10, em que 0 é nada preocupado e 10 é totalmente preocupado, qual é o seu grau de preocupação com as causas indígenas atualmente?

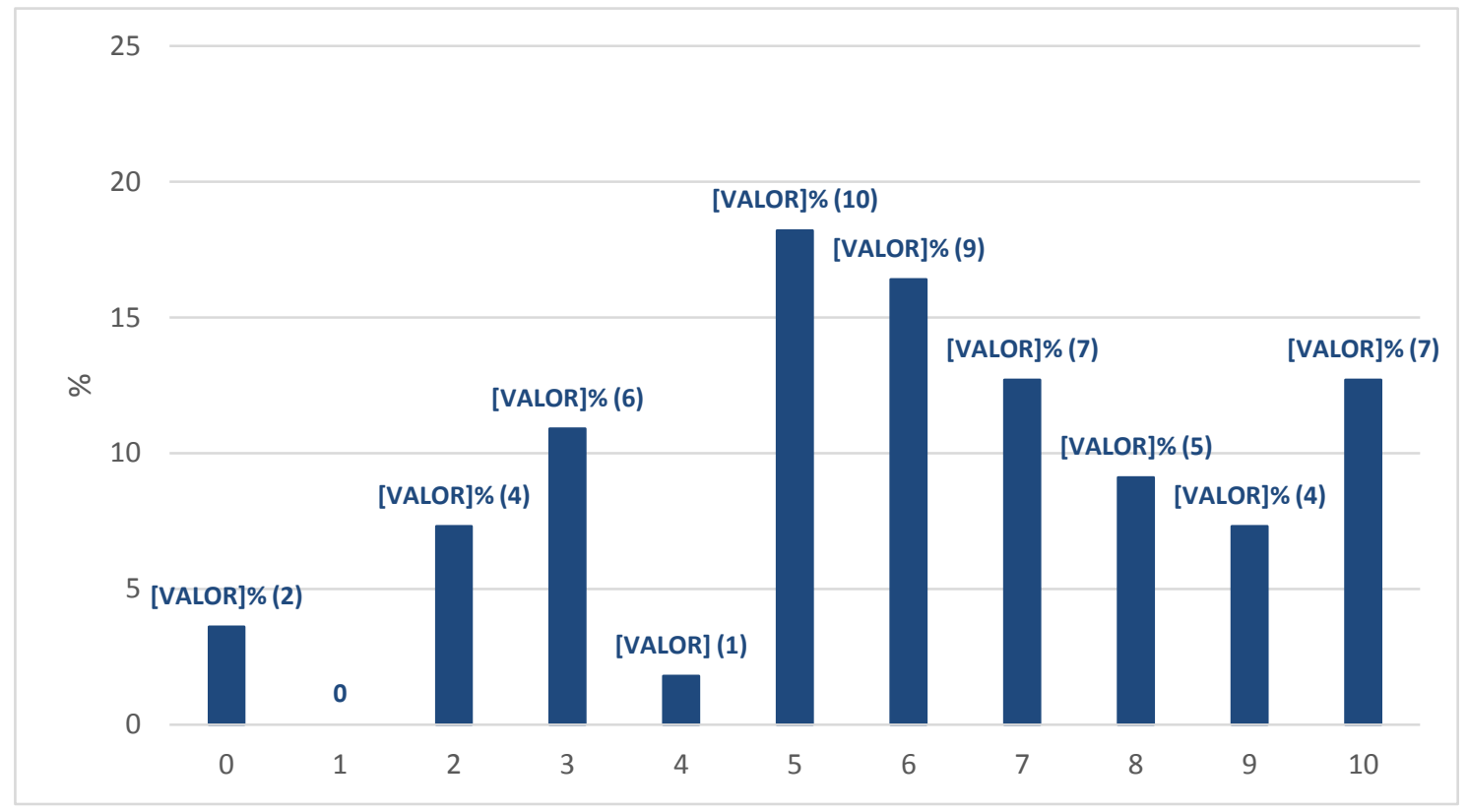

Fonte: DIAS NETO (2019).

Conforme podemos observar no gráfico anterior, as avaliações que denotam por parte dos entrevistados algum nível de preocupação com as causas indígenas agregam o maior número de respostas, revelando um cenário de ambivalência no qual, embora seja prevalente um contexto de baixo conhecimento e invisibilidade indígena, também se configuram os sentimentos de simpatia e aceitação. Nas entrevistas, foi comum os entrevistados iniciarem dizendo que não podiam opinar sobre as comunidades indígenas por não possuírem informações a respeito, e a encerrarem declarando-se favoráveis às questões indígenas, assumindo posição que, à primeira vista soa como contraditória, mas que se torna compreensível ao avaliarmos a inserção do multiculturalismo e a capilaridade dos valores democráticos e dos direitos humanos na sociedade contemporânea. Assim, podemos supor que mesmo que uma pessoa não tenha informações qualificadas para tratar criticamente do racismo ou do feminismo, por exemplo, ela tenderá a assumir, pelo menos formalmente em seu discurso, postura favorável a essas pautas, haja vista sua positiva difusão nos dias de hoje. É o que acontece também com a percepção dos índios na metrópole, principalmente, em função de os grandes centros urbanos tenderem a não possuir uma convivência próxima com as comunidades indígenas que possibilite que os seus moradores estabeleçam relações com o lugar, formando sua percepção a esse respeito com base não em vivências e 
experiências concretas, mas naquilo que lhes é apresentado como informação, seguindo também o curso dos valores gerais contemporâneos.

Atualmente, o que se denota, deste modo, é um ambivalente olhar do habitante da metrópole sobre as comunidades indígenas, de um lado calcado no baixo conhecimento e na invisibilidade e, no outro, na simpatia e aceitação.

\section{Mapas mentais: um olhar histórico e naturalista sobre as comunidades indígenas}

Com o propósito de aprofundar o entendimento sobre a forma na qual a comunidade indígena é percebida no contexto urbano, foram elaborados mapas mentais por parte de alunos do ensino fundamental de uma escola situada na região metropolitana de Belo Horizonte, de modo a possibilitar uma abordagem "holística" do objeto de análise, incorporando em seu escopo também este público, bem como considerar a formação do pensamento de uma próxima geração, no meio urbano, a respeito das comunidades indígenas e oportunizar uma reflexão sobre a própria forma como essa percepção tem sido culturalmente transmitida através da socialização.

Dessa forma, os mapas mentais aplicados junto aos alunos do ensino fundamental da Escola Estadual Guadalajara reforçaram os aspectos debatidos nas entrevistas, convergindo para a composição de uma visão do índio nos centros urbanos, sobretudo, pautada na vinculação das comunidades indígenas aos elementos naturais, e numa visão que tende a ser decorrente da abordagem estabelecida pela educação formal através dos livros de História, que se restringem a tratar da questão indígena nos tempos do processo de colonização brasileiro.

Assim, seguindo o princípio de agrupamento temático dos mapas mentais de Kozel (2018), os mapas representativos das comunidades indígenas possibilitaram o entendimento de dois aspectos fundamentais a respeito da percepção sobre as comunidades que se tem na metrópole, que deram origem aos agrupamentos discriminados a seguir e que, destaca-se, também foram evidenciados nas entrevistas aplicadas com os moradores de Belo Horizonte:

- Percepção sobre os modos de vida indígenas;

- Etnogênese e indianidade: reflexão sobre o que seja o "índio legítimo";

Esses dois agrupamentos interpenetram-se, pois, a percepção sobre os modos de vida indígenas revela uma expectativa sobre a indianidade e etnogênese das 
comunidades, em uma reflexão que perpassa a ideia do que seja o "índio legítimo", que na percepção dos sujeitos na composição dos mapas mentais estaria vinculado à adoção de hábitos de vida tradicionais e calcado na profunda integração com a natureza, que formata na mente do cidadão metropolitano a noção do "índio imaginado".

Destarte, a percepção sobre os modos de vida indígenas é demonstrada pelas crianças em Belo Horizonte através de desenhos que retratam as comunidades empregando modos de vida especificamente indígenas, por intermédio da representação de artefatos e costumes típicos da cultura indígena na sua acepção mais clássica e, em certa medida, generalizante e "estereotipada", como, por exemplo, arcos e flechas, lanças, vestimentas tradicionais, utilização de fogueiras, ocas, colares, etc., como representado nos mapas seguintes.

Mapa Mental 1 - Mapa mental de aluno Mapa Mental 2 - Mapa mental de aluno representando que entende ser uma representando que entende ser uma comunidade indígena comunidade indígena

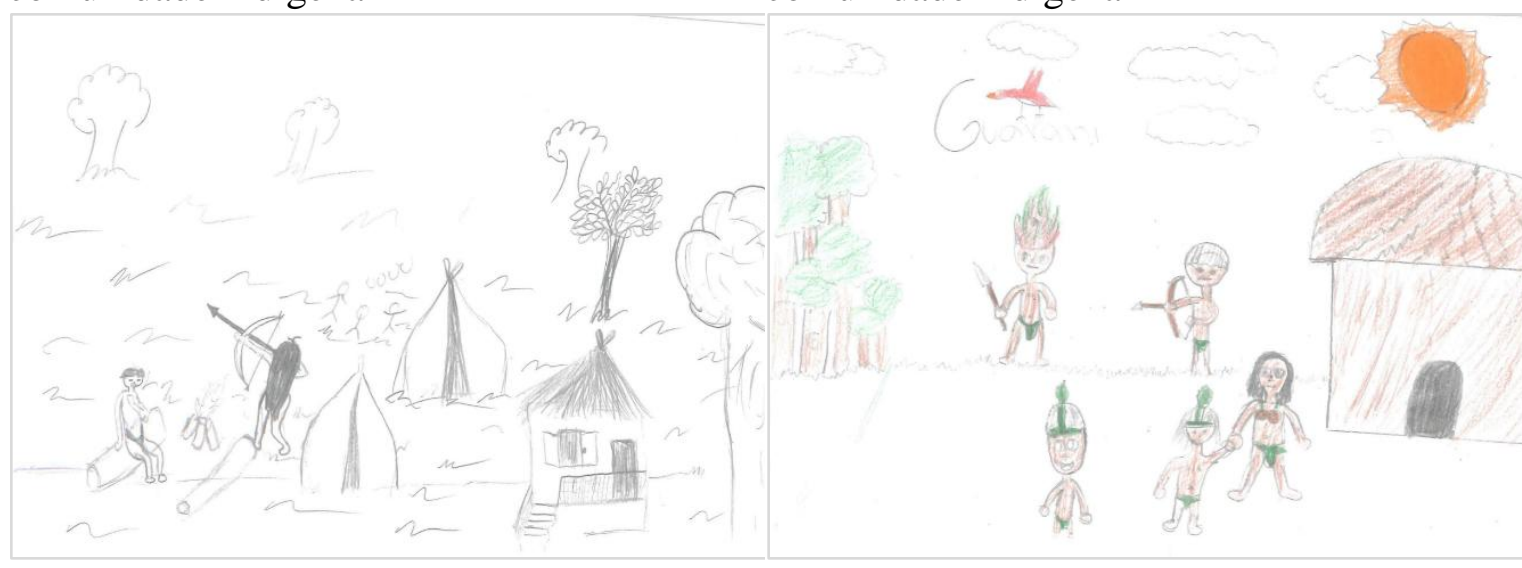

Fonte: DIAS NETO, 2019.

Fonte: DIAS NETO, 2019.

E o que notamos é que prevalece, de fato, na percepção dos alunos da Escola Estadual Guadalajara a imagem das comunidades indígenas dos tempos de colonização construídas através da História. A imagem das comunidades indígenas demonstrada pelos mapas retrata os modos de vida tradicionais indígenas, ajudando-nos também a refletir sobre a indianidade e etnogênese dessas comunidades, trazendo elementos recorrentes na percepção estabelecida sobre as comunidades indígenas. A esse respeito, Lima e Almeida (2010) destacam que: 
As atuais representações sociais dos índios foram construídas pelos não índios ao longo da história de contato que se inicia com o descobrimento do Brasil e se estende com a colonização a que eles foram submetidos e que culmina, nos dias de hoje, com a sua invisibilização e exclusão moral e social. (LIMA; ALMEIDA, 2010, p. 17-18, grifo nosso).

Seguindo as diretrizes da Metodologia Kozel (KOZEL, 2018), identificamos nos mapas analisados as formas de representação dos elementos nas imagens, que se estabeleceram através de ícones e figuras representativas da cultura indígena por meio de desenhos que revelam os aspectos anteriormente debatidos, correlatos aos modos de vida, à etnogênese e a indianidade das comunidades indígenas.

Ademais, como parte da aplicação da Metodologia Kozel, buscamos ainda avaliar a distribuição dos elementos nas imagens, que se estabeleceram majoritariamente de forma horizontal, embora haja também, em menor escala, desenhos em perspectiva e verticais. É sugestivo notar que os desenhos horizontais oportunizam a compreensão das especificidades presentes no imaginário dos indivíduos de forma mais aprofundada, pois, ao optarem por registrar determinado aspecto, fica evidenciada a sua importância. Em relação a esta avaliação, é importante sublinhar que os mapas mentais que retratam a comunidade indígena trazem os elementos percebidos pelos alunos presentes no imaginário das crianças a respeito desse lugar, ou aquilo que eles esperavam que assim se fizesse. Por essa razão, os mapas mentais estão permeados por índios com suas vestimentas tradicionais ou mesmo nus, arcos e flechas, lanças, ocas e outros aspectos característicos - e, em certa medida estereotipados - da cultura indígena.

Além disso, tomamos também por referência, neste tópico, a aplicação da Metodologia Kozel por Kashiwagi (2018), que elaborou um quadro para identificar a especificidade dos ícones presentes nos mapas mentais analisados pelo autor. Desta maneira, procedemos a sistematização das informações através da tabela seguinte.

Conforme apresentado na tabela 1, o ícone de maior representatividade nos mapas mentais é a oca, habitação tradicionalmente indígena, presente em todos os desenhos analisados. Isso significa que, na percepção das crianças da Escola Estadual Guadalajara, as comunidades indígenas são aquelas nas quais os índios vivem nas ocas, o que nos leva a refletir, novamente, sobre a etnogênese das comunidades nas quais o tipo de construção que predomina é a de alvenaria, como é o caso de parcela considerável das comunidades indígenas localizadas fora da região amazônica. 
Outro fator importante na percepção da metrópole sobre as comunidades indígenas observado nos mapas mentais é a vinculação estabelecida entre os índios e o naturalismo. Neste sentido, os ícones representando árvores, arbustos, flores e montanhas foram os elementos naturais mais presentes nos desenhos. Ademais, "paisagem natural" foi o agrupamento em que foram reportadas o maior número de categorias, perfazendo um total de oito elementos - comparativamente, foram reportados quatro elementos humanos e um elemento da paisagem construída. Isso significa que no imaginário das crianças em Belo Horizonte, as comunidades indígenas se caracterizam pela interação entre índios e natureza.

Quadro 1 - Análise dos Mapas Mentais elaborados pelos alunos da Escola Estadual Guadalajara representando comunidades indígenas, seguindo os princípios da Metodologia Kozel.

\begin{tabular}{|c|c|c|c|c|c|c|c|c|c|c|c|c|c|c|c|c|c|c|}
\hline & \multirow{2}{*}{\begin{tabular}{|c|} 
Elementos \\
identificados \\
pelos autores
\end{tabular}} & \multicolumn{17}{|c|}{ ENTREVISTADOS } \\
\hline & & 1 & 2 & 3 & 4 & 5 & 6 & 7 & 8 & 9 & 10 & 11 & 12 & 13 & 14 & 15 & 16 & 17 \\
\hline \multirow{8}{*}{$\begin{array}{c}\text { Elementos } \\
\text { da } \\
\text { paisagem } \\
\text { natural }\end{array}$} & Sol & $x$ & $X$ & & $x$ & & & $\mathrm{X}$ & & & & $\mathrm{X}$ & & $x$ & & $\mathrm{X}$ & $\mathrm{X}$ & $\mathrm{X}$ \\
\hline & Lua & & & $X$ & & & & & & & & & & & & & & \\
\hline & Céu & & & & & & & & $X$ & & & & & & & & & \\
\hline & Nuvens & & & & $X$ & & & $X$ & & & & & & $X$ & & $X$ & $X$ & $X$ \\
\hline & Animais $^{1}$ & $X$ & & & $x$ & & & & & & & $X$ & & $x$ & & $x$ & & \\
\hline & $\begin{array}{c}\text { Árvores, } \\
\text { arbustos, } \\
\text { flores, } \\
\text { montanhas }\end{array}$ & & & $\mathrm{X}$ & $X$ & & $X$ & $X$ & $X$ & $\mathrm{X}$ & & $X$ & $X$ & $X$ & $\mathrm{X}$ & & $X$ & $X$ \\
\hline & $\begin{array}{l}\text { Rio, lago, } \\
\text { cachoeira }\end{array}$ & & & & & & $X$ & & & & & & & & $X$ & $X$ & & \\
\hline & $\begin{array}{l}\text { Fruteiras } \\
\text { (coqueiro, } \\
\text { bananeira) }\end{array}$ & & & & & & & $\mathrm{X}$ & & & & & & & & & & \\
\hline $\begin{array}{c}\text { Elementos } \\
\text { da } \\
\text { paisagem } \\
\text { construída }\end{array}$ & Oca(s) & $X$ & $x$ & $X$ & $x$ & $x$ & $x$ & $\mathrm{X}$ & $\mathrm{X}$ & $\mathrm{X}$ & $X$ & $X$ & $\mathrm{X}$ & $X$ & $\mathrm{X}$ & $X$ & $x$ & $X$ \\
\hline \multirow{4}{*}{$\begin{array}{l}\text { Elementos } \\
\text { humanos }\end{array}$} & Índios(as) & $X$ & & $X$ & $x$ & $X$ & $x$ & $\mathrm{X}$ & $X$ & $X$ & & $X$ & $X$ & & $X$ & & & $\mathrm{X}$ \\
\hline & Fogo & & $X$ & $\mathrm{X}$ & & $x$ & $X$ & & $X$ & $X$ & & $X$ & $X$ & & & & $X$ & $X$ \\
\hline & $\begin{array}{c}\text { Vestimentas } \\
\text { tradicionais } \\
\text { indígenas }\end{array}$ & & & $X$ & $X$ & $x$ & & $X$ & $x$ & $X$ & & & $X$ & & & & & $X$ \\
\hline & $\begin{array}{c}\text { Artefatos } \\
\text { indígenas }^{2}\end{array}$ & & & $x$ & $X$ & $x$ & & $X$ & $X$ & $X$ & & $X$ & & & & $X$ & & $X$ \\
\hline
\end{tabular}

Fonte: DIAS NETO, 2019.

Em síntese, o que os mapas mentais aplicados na escola situada na região metropolitana revelam é a composição de uma percepção comum na metrópole sobre as comunidades indígenas, que segue na linha das abordagens de Schneider e Verás Neto 
(2015) sobre a percepção dos índios em Porto Alegre, e de Lima e Almeida (2010) a respeito dos índios em Sergipe, nas quais o baixo conhecimento desencadeia um processo de invisibilidade que, por sua vez, acaba por gerar um distanciamento físico e cultural determinante na configuração da percepção que se desenha nos centros urbanos sobre as comunidades indígenas, as quais se baseiam, principalmente, na visão histórica (clássica, estática e padronizada) da figura do índio e das próprias comunidades, acarretando em uma demanda por parte da sociedade em geral a respeito de um "índio legítimo" que, consequentemente, deslegitima a indianidade das comunidades indígenas não tipificadas no padrão esperado (ou idealizado), conforme revelado no discurso e mapas mentais no contexto urbano.

\section{Considerações Finais}

Na perspectiva do sociólogo alemão Georg Simmel, o distanciamento físico é um fator de relevância na construção das representações sobre o outro (SIMMEL, 2005). Esse distanciamento, conforme o autor, implica, também, em um distanciamento simbólico. E isto foi o que pudemos perceber no âmbito desta pesquisa, uma vez que as representações das comunidades indígenas na metrópole apontaram para um distanciamento físico que se reflete também em um distanciamento simbólico, sendo a proximidade territorial um fator determinante na composição da percepção que se estabelece sobre as comunidades indígenas no Brasil, conforme destacam Lima e Almeida (2010).

Torres e cols. (2007) realizaram um estudo das representações sobre os índios em duas cidades de Goiás: uma onde existe um aldeamento urbano e os índios frequentam as escolas públicas e outra onde não existe nenhum tipo de contato entre indígenas e não-indígenas. As autoras observaram que existe mais preconceito contra os índios na cidade onde há mais contato com eles do que na cidade onde não há contato. As explicações para esse dado abordam a percepção de competição por recursos materiais e simbólicos entre índios e nãoíndios quando convivem mais próximos (LIMA; ALMEIDA, 2010, p. 20).

Neste trabalho, o que temos como resultado da aproximação geográfica é, dessarte, convergente com os aspectos observados também por Torres et al. (2007), no sentido de que as unidades de distância e proximidade interferem nas relações e, aqui 
acrescentamos, na percepção dos sujeitos na composição das representações a respeito das comunidades indígenas.

Um fator que se mostrou determinante na composição da percepção sobre as comunidades indígenas se refere à etnogênese, aqui tratada na perspectiva de Mota (2008) como o reconhecimento da indianidade das comunidades e dos índios por parte da sociedade, elemento que permeou, de forma direta e indireta, o discurso dos entrevistados e os mapas mentais, como atributos característicos de um índio imaginado, cuja construção se estabelece na percepção através da abordagem histórica do período do Brasil colonial, baseada nos registros clássicos dos primeiros contatos entre brancos e índios.

E é assim a imagem que se desenhou desde aquele tempo, em que os índios eram retratados a partir de seus hábitos de vida e costumes, com destaque para a relação de integração com a natureza, que ainda hoje permeia o imaginário das pessoas. Os processos de aculturação e interação entre sociedade brasileira e comunidades indígenas parecem-nos, então, pouco explorados, uma vez que as entrevistas e mapas mentais revelaram sempre a expectativa de vislumbrar, nas comunidades indígenas contemporâneas, o "índio imaginado", como aquele genericamente retratado nos livros de História, fator inclusive materializado no discurso dos próprios entrevistados, como destacado ao longo deste artigo.

Temos, portanto, que a reflexão sobre um "índio imaginado" é algo que permeia a consciência dos sujeitos na composição da percepção que se estabelece sobre as comunidades indígenas. O que quer dizer que quando uma comunidade indígena é percebida por algum indivíduo não-índio, no campo da cognição, essa avaliação sobre a legitimidade indígena intermediará a relação entre esse indivíduo e o lugar, pois, a imagem recorrente do índio historicamente construída é algo enraizado na percepção que se estabelece no senso comum sobre as comunidades indígenas brasileiras, sendo a noção do "índio legítimo" algo basilar nessa dinâmica.

\section{Referências}

AMORIM FILHO, O. B.. O contexto teórico do desenvolvimento dos estudos humanísticos e perceptivos na geografia. In: AMORIM FILHO, O. B.; CARTER, H.; KOHLSDORF, M. E.. Percepção ambiental: contexto teórico e aplicações ao tema urbano. Belo Horizonte, Departamento de Geografia, IGC/UFMG, Publicação Especial núm. 5, 1987.

CLAVAL, P.. Introdução. In: A geografia cultural. Florianópolis: Editora da UFSC, 2014. 4 ed. rev. p. 17-23. 
DEUS, J. A. S.; RODRIGUES, L. M.. Reinvenção da identidade cultural, protagonismo etnopolítico e interações com o turismo dos índios Pataxó(s) de Carmésia (Estado de Minas Gerais, Brasil). AGÁLIA - Revista de Estudos na Cultura - Turismo em Terras Indígenas, 2015. p. 203-223.

DIAS NETO, J.. Aqui e Lá: Olhares e fronteiras entre a comunidade indígena Pataxó e a sociedade envolvente no município de Carmésia/MG. Dissertação de mestrado apresentada ao Programa de Pós-Graduação em Geografia da Universidade Federal de Minas Gerais/Instituto de Geociências (IGC), 2019. 334 p.

GOODEY, B.; GOLD, J.. Geografia do comportamento e da percepção. Belo Horizonte, Departamento de Geografia, IGC/UFMG, Publicação Especial núm. 3, 1986.

HOLZER, W.. O método fenomenológico: humanismo e construção de uma nova Geografia. In: ROSENDAHL, Z.; CORRÊA, R. L.. Temas e caminhos da Geografia Cultural. Rio de Janeiro: EdUERJ, 2010. p. 37-71.

KOZEL, S.. As linguagens do cotidiano como representações do espaço: uma proposta metodológica possível. In: 12 Encuentro de Geógrafos de América Latina, Montevidéo. Anais. Montevidéo, 2009.

KOZEL, S.. Mapas Mentais: Dialogismo e Representações. 1 ed. Curitiba: Appris, 2018.

LIMA, M. E. O.; ALMEIDA, A. M. M.. Representações sociais construídas sobre os índios em Sergipe: ausência e invisibilização. Paideia, vol. 20, num. 45, jan-abr. 2010. p. 17-27.

MOTA, C. N.. Ser indígena no Brasil contemporâneo: novos rumos para um velho dilema. Revista Ciência e Cultura, vol. 60, num. 4, 2008, São Paulo. p. 22-24.

RIBEIRO, D.. Os índios e a civilização: a integração das populações indígenas no Brasil moderno. São Paulo: Companhia das Letras, 1996.

SCHNEIDER, G. S. S.; VERÁS NETO, F. Q.. A (in)visibilidade dos direitos indígenas nos grandes centros urbanos: um olhar sobre os indígenas na cidade de Porto Alegre. $\mathbf{1}^{\mathbf{0}}$ Colóquio Internacional de História Cultural da Cidade, Porto Alegre, 9 a 11 de março de 2015. Disponível em:

<http://www.ufrgs.br/gthistoriaculturalrs/26CDGiseldaSchneider_FranciscoQuintanilha.pdf> Acesso em 03 de fevereiro de 2019.

SIMMEL, G.. A metrópole e a vida mental. In: VELHO, O. G.. O fenômeno urbano. Rio de Janeiro: Zahar Editores, 1973. p. 11-25.

\section{Agradecimentos}

( Capes, CNpq, Fapesb, ) 